\title{
Insight into kinetics and mechanisms of AOT vesicle adsorption on silica in unfavorable conditions
}

Julie WOLANIN ${ }^{a}$, Loïc BARRE ${ }^{a}$, Christine DALMAZZONE * ${ }^{a}$, Didier FROT ${ }^{a}$, Jacques JESTIN $^{b}$, Hubert PERROT ${ }^{c}$, Daniela BAUER ${ }^{a}$

${ }^{\text {a }}$ IFP Energies nouvelles, 1 et 4 avenue de Bois-Préau, 92852, Rueil Malmaison, France

${ }^{b}$ Laboratoire Léon Brillouin, CNRS-CEA, 91191 Gif-sur-Yvette, France

c Sorbonne Université, CNRS, Laboratoire Interfaces et Systèmes Electrochimiques, LISE, 75005 Paris, France

\section{Keywords}

Surfactant adsorption, AOT, $\mathrm{NaCl}$, vesicle, adsorption kinetics, structural rearrangement, silica, QCM-D, neutron reflectivity

\begin{abstract}
The structure of adsorbed surfactant layers at equilibrium state has already been investigated using various experimental techniques. However, the comprehension of the formation of structural intermediates in non-equilibrium states and the resulting adsorption kinetics still remains a challenging task. The temporal characterization of these intermediate structures provides further understanding of the layer structure at equilibrium and of the main interactions involved in the adsorption process. In this article, we studied adsorption kinetics of AOT vesicles on silica at
\end{abstract}


different $\mathrm{pH}$ at ambient temperature. AOT vesicles were formed in a brine solution. Quartz crystal microbalance with dissipation monitoring (QCM-D) was used to obtain information on the kinetics of surfactant adsorption and on the structure of the adsorbed layer at the equilibrium state. Additionally, neutron reflectivity experiments were performed to provide a detailed description of the mean surfactant concentration profile normal to the surface at equilibrium. Results suggest that vesicles in the bulk influence the adsorption mechanisms. In acidic conditions, after a time dependent structural rearrangement step followed by the rupture of initially adsorbed vesicles, the formation of a bilayer was observed. At intermediate and basic $\mathrm{pH}$, in spite of the electrostatic repulsion between the negatively charged surfactants and silica, results demonstrated the existence of an adsorbed layer composed of AOT vesicles. Vesicles are more or less closely packed depending on the $\mathrm{pH}$ of the solution. Results show non-negligible influence of $\mathrm{NaCl}$ addition at $\mathrm{pH}$ values where adsorption is initially inhibited. Vesicle adsorption at intermediate and basic $\mathrm{pH}$ is probably due to the combination of attractive van der Waals interactions promoted in high ionic strength systems and the formation of hydrogen bonds. Interpretation of adsorption kinetics gave insight into adsorption mechanisms in an electrostatic repulsion environment. 


\section{Introduction}

Surfactant adsorption occurs in various industrial processes such as cosmetic formulations, enhanced oil recovery, dispersion or detergency processes... In some cases, surfactant adsorption is undesired, as for example in enhanced oil recovery (EOR) processes, where unpurified surfactants are injected in the reservoir rock in order to reduce the interfacial tension between oil and water, and adsorption limitation becomes an important issue. Adsorption results from the combination of various surfactant/substrate interactions like electrostatic and van der Waals interactions or hydrogen bonding. Consequently, surfactants can form different adsorbed layer structures $^{1-7}$. Most of the time, surfactant monomers adsorb at the solid/liquid interface, particularly in the case of strong attractive interactions ${ }^{1-6,8-10}$. Monomers organize at the interface and form different structures which depend on the nature of the surface: hydrophilic (cylinders, spheres, bilayers...) or hydrophobic (hemicylinders, hemispheres, monolayers...). Generally, the surface is saturated at the Critical Micellar Concentration (CMC). However, in some particular cases, bulk surfactant aggregates can also directly adsorb at the solid surface ${ }^{4,11-13}$.

In previous works, systems have been adequately chosen in order to have an electrostatic attractive environment as it is the case for the adsorption of charged surfactants on oppositely charged surfaces ${ }^{6,10,14-17}$. Only few studies have characterized adsorption mechanisms in repulsive environments ${ }^{18-27}$ as it is the case for the adsorption of surfactants having the same charge as the solid surface.

In the present article, we investigated adsorption of negatively charged AOT (sodium bis(2ethyl-1-hexyl)sulfosuccinate) vesicles on silica, a substrate widely used in the industry. The structure of the adsorbed layer was analyzed at different $\mathrm{pH}$ as the latter modifies the surface charge of silica. Indeed, adsorption kinetics and the resulting adsorbed layer are clearly affected 
by the $\mathrm{pH}$ of the bulk solution. We note that the presence of impurities in the investigated surfactant solution has to be considered carefully, quantifying if their effect can be negligible or not, as it may act as a rival regarding the adsorption process ${ }^{28,29}$. Because of their very high surface activity (stronger than that of the main component), it becomes very difficult even impossible to purify the surfactant solution to a sufficient level ${ }^{29}$, as particularly AOT is known to be an efficient scavenger of divalent ions.

In the literature, many studies have reported mechanisms of phospholipidic vesicle adsorption on hydrophilic surfaces ${ }^{30-33}$. We can point out that, in the case of surfactant vesicles, the monomer concentration in solution is much larger compared to lipid vesicles and the exchange rate between monomer and surfactant vesicle is also extremely fast. Two ideal structures are generally reported and correspond either to the adsorption of intact phospholipidic vesicles or to the formation of planar bilayers. Mixed states can also be obtained leading to an adsorbed layer composed of both intact vesicles and bilayer patches individually adsorbed ${ }^{32}$. A large number of studies have demonstrated that phospholipidic vesicle rupture can be favored by the modification of experimental conditions such as temperature increase ${ }^{31,34,35}$, addition of divalent ions ${ }^{36-39}$ or fusogenic agents ${ }^{31,34}$, vesicle size and composition ${ }^{37,40,41}$, ionic strength increase by salt addition ${ }^{36}$ or $\mathrm{pH}^{36,42}$. Cremer et $a l^{43}$ have shown that the formation of a bilayer on silica from negatively charged phospholipid vesicles was favoured at low $\mathrm{pH}$ and elevated salt concentration.

The Quartz Crystal Microbalance with Dissipation monitoring technique (QCM-D) gives information on the kinetics of surfactant adsorption and may give details on the morphology and the global structure of the adsorbed layer. QCM-D is an appropriate tool for this study as it provides a qualitative estimation of the temporal evolution of the structure of surfactant aggregates adsorbed on the surface ${ }^{44-46}$. The formation of a monolayer of unruptured phospholipid vesicles or a planar 
bilayer has already been investigated by QCM-D ${ }^{37,38,40-42,47-49}$. Monotonically growing signals (frequency and dissipation) were generally observed in the first case (Figure 1B), whereas a two phase process was usually detected in the second one, corresponding to the rupture of vesicles once a critical concentration of vesicles on the surface has been reached (Figure 1A) ${ }^{47}$.
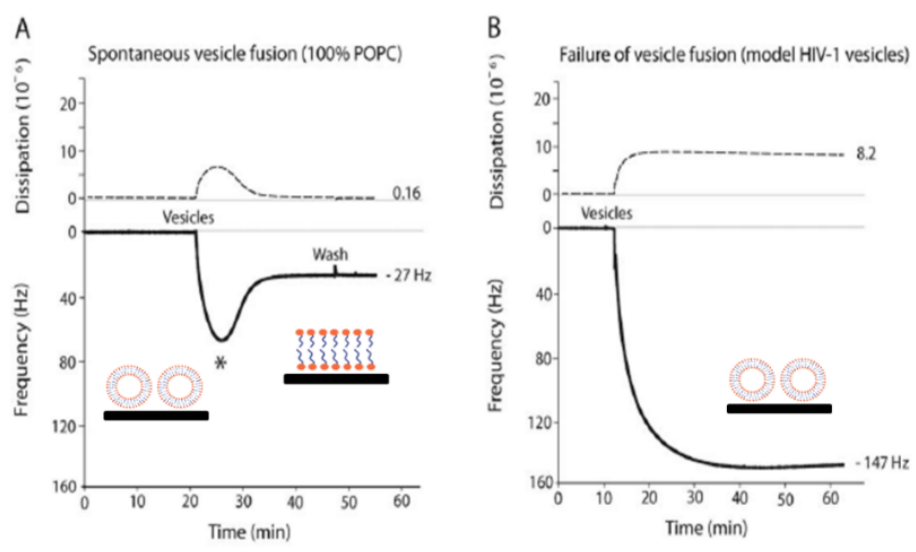

AH peptide-induced vesicle fusion (model HIV-1 vesicles)

Figure 1: Adsorption of phospholipidic vesicles on hydrophilic surfaces. Typical QCM-D curves for the formation of A) a bilayer B) a monolayer of unruptured vesicles. Frequency (solid line) and dissipation (dashed line) versus time variations at the third overtone. * critical surface coverage $^{47}$. Reproduced with permission of RSC.

Neutron reflectivity experiments allow us to extend investigations into the details of the structure of the adsorbed layer at the nanometer-scale. The two ideal structures previously cited lead to pronounced differences in reflectivity profiles ${ }^{27,49-52}$.

Whereas equilibrium structures have been investigated for a long time, only little is known on surfactant adsorption kinetics and morphological transitions occurring between the initial state and the thermodynamic equilibrium. Only a small number of studies using different experimental techniques (depletion method ${ }^{23,53,54}$, X-ray photoelectron spectroscopy ${ }^{4}$, optical reflectometry ${ }^{55,56}$, $\mathrm{AFM}^{57-59}$, scanning angle reflectometry ${ }^{60}, \mathrm{QCM}^{\mathrm{D}}{ }^{56,61,62}$, ellipsometry ${ }^{63,64}$, NMR relaxometry ${ }^{65}$, FTIR $^{20,23,53}$ ) have reported the kinetics of surfactant adsorption. The characterization of the 
temporal evolution of surfactant aggregates remains ambitious due to non-equilibria and the time scale on which morphological transitions take place.

Usually, the temporal evolution of the surfactant adsorption process consists of three distinct regimes $^{23}$ : an initial fast adsorption rate (diffusion of surfactants towards the interface), followed by an intermediate slow adsorption rate phase (surfactant rearrangements at the interface) and a final plateau regime (equilibrium state). The time extent of each state depends on the physicochemical conditions. Only few articles refer to the relation between adsorption kinetics and physico-chemical parameters of the system ${ }^{54}$. Chen et $a .^{4}$ stated that the kinetics and the equilibrium structures were controlled, among other parameters, by the combination of hydrophobic and molecular packing contributions, but also by the achievement of a local electroneutrality.

Thus, the general objective of this work is to provide further understanding of AOT vesicle (formed at high ionic strength) adsorption mechanism on silica at different $\mathrm{pH}$ values. Complementary information (kinetic monitoring and structure of the adsorbed layer at equilibrium) are obtained by the combination of QCM-D and neutron reflectivity experiments.

\section{Materials and Methods}

\section{Materials}

Aerosol-OT (Figure 2), usually named AOT (sodium bis(2-ethyl-1-hexyl) sulfosuccinate, $\mathrm{C}_{20} \mathrm{H}_{37} \mathrm{NaO}_{7} \mathrm{~S}$ ) was purchased from Sigma-Aldrich (BioXtra, $\geq 99 \%$, product number D4422, batch no. SLBL8632V) and used without further purification. In the certificate of analysis provided by the supplier, cationic impurities have been quantified: potassium $<0.01 \%$, calcium, lead and aluminum $<0.001 \%$, magnesium, iron, zinc, copper and phosphorus $<0.0005 \%$, and insoluble matter $<0.1 \%$. 


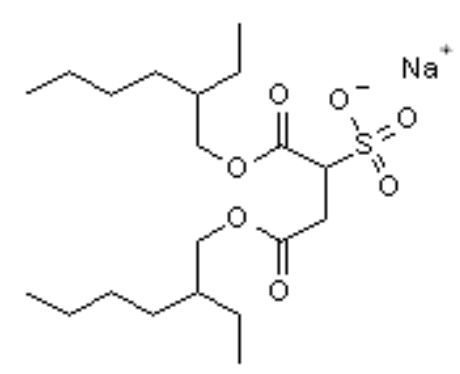

Figure 2: Chemical structure of AOT

Water was obtained from a Millipore system and $\mathrm{D}_{2} \mathrm{O}$ was purchased from Eurisotop (99.96\% D).

$\mathrm{NaCl}$ was purchased from Fisher Chemical with a percent purity of $99 \%$. The principal impurities were calcium $(0.005 \%)$, iodide $(0.002 \%)$ and magnesium $(0.005 \%)$.

Usually, $\mathrm{AOT}$ and $\mathrm{NaCl}$ are purified to prevent competitive surface agent binding. Tummala et $a l .{ }^{66}$ have demonstrated that the binding of impurities to the surface can modify the adsorption process. The importance of impurities (coming from $\mathrm{AOT}$ or $\mathrm{NaCl}$ ) on the adsorption process has been assessed from the surface tension plots as discussed by Li et $a l .{ }^{67}$. Plots are presented in the Supporting Information (Figure S1). The comparison of the surface tension slopes with those obtained by Li et $a l .{ }^{67}$ (Figure S2) enables us to highlight characteristic features of an impure AOT. This observed trend results from divalent cation impurities which are present in the surfactant layer at the air/water interface. Thus, we suppose calcium and magnesium being the main impurities that can have a non-negligible contribution on the adsorption measurements.

AOT was diluted in a brine solution composed of $15 \mathrm{~g} / \mathrm{L} \mathrm{NaCl}\left(0.26 \mathrm{~mol} / \mathrm{dm}^{3}\right)$. Above the CVC $\left(\mathrm{CVC}=0.09 \mathrm{~g} / \mathrm{L}=0.2 \mathrm{mmol} / \mathrm{dm}^{3}\right)$, the AOT/brine solution was mainly composed of small unilamellar vesicles (14 nm diameter) with a bilayer thickness of $2.7 \mathrm{~nm}$. Details on the multiscale vesicle's characterization of the solution can be found in the litterature ${ }^{68}$. 
According to Iler et $a l .^{69}$, the silica surface has amphoteric hydroxyl sites and its point of zero charge (PZC) is supposed to be close to 2 . The $\mathrm{pH}$ values for this study were chosen as a function of this PZC. All adsorption measurements were performed at $20^{\circ} \mathrm{C}$ at three different $\mathrm{pH}$ (acidic $\mathrm{pH} \sim 1.5$, intermediate $\mathrm{pH} \sim 6$ and basic $\mathrm{pH} \sim 9$ ). The AOT and brine concentrations were fixed, respectively, to $2.7 \mathrm{CVC}\left(0.24 \mathrm{~g} / \mathrm{L}=0.54 \mathrm{mmol} / \mathrm{dm}^{3}\right)$ and $15 \mathrm{~g} / \mathrm{L} \mathrm{NaCl}$. Details on silica surfaces used in this work for QCM-D and neutron reflectivity experiments are given in the appropriate method section.

The $\mathrm{pH}$ values were adjusted by the addition of $\mathrm{NaOH}$ or $\mathrm{HCl}$. The $\mathrm{pH}$ of each solution was measured before and after adsorption measurements in order to confirm their stability over time. DLS measurements confirmed that there was only a negligible influence of the $\mathrm{pH}$ on the AOT vesicle size.

Finally, bulk density and viscosity were only minimally impacted by the addition of surfactant to the brine solution (Table 1).

Table 1: Density and viscosity of the investigated solutions

\begin{tabular}{|l|l|l|}
\hline & Density & Viscosity $[\mathrm{cP}]$ \\
\hline Brine: $15 \mathrm{~g} / \mathrm{L} \mathrm{NaCl}$ & 1.01 & 1.0 \\
\hline AOT $2.7 \mathrm{CVC}$ & 1.01 & 1.2 \\
\hline
\end{tabular}

\section{Methods}

\section{Quartz Crystal Microbalance with Dissipation Monitoring (QCM-D)}

A QCM-D (flow model E1, Q-sense, Sweden) was used to study the adsorption of AOT on silica. The technique is based on the piezoelectric properties of a gold-coated quartz crystal having a fundamental resonance frequency $f_{0}$ of $5 \mathrm{MHz}$. The surface of the sensor consists of a $50 \mathrm{~nm}$ amorphous silicon dioxide layer (Qsense, QSX 303) sputtered onto the gold-coated quartz crystal. 
The adsorption of surfactants on the quartz crystal surface decreases the resonance frequency of the crystal. The acquisition of experimental data is done simultaneously at different overtones, $n$, from 3 to 13. Normalized shifts in frequency $\left(\Delta f_{n} / n\right)$ due to adsorption are proportional to the adsorbed mass $(\Delta m)$ according to the Sauerbrey ${ }^{46,70}$ relation:

$$
\Delta m=\frac{-K \Delta f_{n}}{n}
$$

with $K$ being the mass sensitivity constant $\left(K=17.7 \mathrm{ng} \cdot \mathrm{cm}^{-2} \cdot \mathrm{Hz}^{-1}\right.$ at $\left.5 \mathrm{MHz}\right)$ and $n$ the overtone number. In the Sauerbrey model, the adsorbed mass is assumed to form a thin rigid film uniformly distributed on the quartz crystal surface with $\Delta m$ being smaller than $2 \%$ of the mass of the crystal. In this case, the normalized shifts in frequency are overtone independent and all $\Delta f_{n} / n$ versus time curves overlay.

Dissipation represents the energy that the oscillating system loses during one period of oscillation $^{62}$. The dissipation factor $D$ is defined as ${ }^{71}$ :

$$
D=\frac{E_{\text {dissipated }}}{2 \pi E_{\text {stored }}}
$$

where $E_{\text {dissipated }}$ represents the energy loss due to the adsorbed layer during one oscillation period and $E_{\text {stored }}$ is the total energy stored in the harmonic oscillator. When the power of the oscillating crystal is turned off, the amplitude of the oscillation decreases with time with an exponential envelope due to the crystal's damping. $D$ is related to the decay time $\tau$ of the exponentially damped sinusoidal signal ${ }^{62}$ :

$$
D=\frac{1}{\pi f_{0} \tau}
$$

The Sauerbrey model stays valid ${ }^{72}$ if $\Delta D_{n} / n<2 \times 10^{-6}$.

In the case of the adsorption of a non-rigid layer, the Sauerbrey model is not valid and $\Delta f_{n}(t) / n$ (but also $\left.\Delta D_{n}(t) / n\right)$ curves do not overlay. If the non-rigid layer is homogeneous, well-organized 
and large enough, it can be analyzed using viscoelastic models (for example the Kelvin-Voigt model $)^{46,62,73,74}$.

In the case of a soft thin heterogeneous layer, the interpretation of experimental data is more complicated as it requires the consideration of complex hydrodynamic contributions. Dissipation analysis is used to characterize such soft films. Johannsmann et $a l^{75}$ have demonstrated that dissipation is mainly related to the geometry and the type of attachment of the adsorbed objects on the surface. High dissipation values are measured in the case of a soft layer with limited contact zone between the adsorbed objects and the quartz surface. Moreover, slipping of the adsorbed layer and high degree of mobility of the attached objects also cause dissipation.

Thus, the joint measurement of frequency and dissipation provides information on the structural and morphological properties of the adsorbed layer and may predict the degree of interactions between the adsorbed surfactants and the solid surface. To summarize, frequency shifts are mainly due to the total adsorbed mass which includes both surfactant and hydrodynamically coupled water. Dissipation shifts can give information on the global structure of the adsorbed layer (rigid or soft) and indicate the degree of interactions of the surfactants with the surface.

More details about the technique can be found elsewhere ${ }^{44,45,76}$.

\section{Bulk effect contribution}

It should be noted that QCM-D is also sensitive to changes in density and viscosity of the injected solution causing a change in the system oscillation. Thus, both frequency and dissipation shifts can be significantly impacted if the density and the viscosity of the surfactant solutions are different from those of the baseline solution. Consequently, the estimation of the adsorbed mass by QCM-D could be overestimated by a large contribution of the bulk, the so-called bulk effect ${ }^{77,78}$. As specified in the Materials section, the low surfactant concentration $(0.24 \mathrm{~g} / \mathrm{L})$ used in this work 
has a minor influence on the viscosity and density. Thus, the contribution of the bulk was supposed to be negligible. We have experimentally confirmed this assumption by significantly increasing the AOT concentration to $5 \mathrm{~g} / \mathrm{L}$ : results give QCM-D curves similar to those obtained with a concentration of $0.24 \mathrm{~g} / \mathrm{L}$.

\section{Silanol groups quantification on the amorphous silicon dioxide layer}

No surface charge measurements have been performed. However, we estimated the number of $\mathrm{OH} / \mathrm{nm}^{2}$ by analysing the adsorption of CTAB (cationic surfactant) on silica substrate (favourable conditions, bilayer formation, see reference ${ }^{61}$ ) at neutral $\mathrm{pH}$. The number of reactive silanol groups has been estimated to $\sim 1.7 \mathrm{OH} / \mathrm{nm}^{2}$. This value is lower than the value of $4.6 \pm 0.5 \mathrm{OH} / \mathrm{nm}^{2}$ reported in the literature (see Zhuralev et $a l .^{79}$ ) for an amorphous silica when the surface is hydroxylated to its maximum degree.

\section{Cleaning Procedure}

Before each experiment, the quartz crystal was cleaned in a hydrochloric acid solution. The quartz was placed for $5 \mathrm{~min}$ in a diluted hydrochloric acid solution, rinsed intensively with pure water and dried in an oven at $40^{\circ} \mathrm{C}$ overnight. This « non-aggressive » cleaning procedure (compared to the one frequently reported in the literature ${ }^{61,80}$ ) has been chosen in order not to damage the silica surface by a too corrosive protocol (as it has been reported by Gutig et $a .^{61}$ ). Our protocol is efficient to remove surfactants previously adsorbed as good repeatability of the measurements has been obtained. To confirm the successful cleaning of the quartz, a brine solution was injected after having obtained a stable baseline with pure water and the recorded frequency and dissipation changes were compared to the theoretical ones calculated using the Kanazawa and Gordon equation ${ }^{77,78}$, considering only the bulk effect. If the deviations were $<2 \%$, the surface was considered to be clean. 


\section{Adsorption kinetics measurements}

All experiments were performed at $20^{\circ} \mathrm{C}$ at a constant flow rate of $0.2 \mathrm{~mL} / \mathrm{min}$. The Reynolds number was low (5.5) and the flow laminar with a transit time of $27 \mathrm{~s}$. Before each experiment, pure water was injected during 30 min to clean the inlet tubing and the flow module to eliminate any contamination from previous studies. The brine solution was injected until a stable baseline was reached. Then, the surfactant solution was injected into the measurement cell and frequency and dissipation shifts at different overtones were simultaneously recorded. We noted that the surfactant solution was well mixed before injection. Once stabilization in frequency and dissipation was reached (named as plateau values, corresponding to a stable signal for $\sim 1 \mathrm{~h}$ ), the brine solution was injected. The desorption process was considered as correctly and completely achieved when all $\Delta f_{n} / n$ and $\Delta D_{n} / n$ curves regained baseline values.

\section{Neutron Reflectivity}

Neutron reflectivity experiments were performed at Laboratoire Léon Brillouin using Time of Flight Reflectometer Hermès. Specular neutron reflectivity experiments allow the determination of the structure and composition of the adsorbed layer formed at the equilibrium state. Indeed, the low contrast of surfactant aggregates does not allow us to characterize the structural intermediates. A layer of vesicles is poorly contrasted as it is mainly composed of water. In the literature, the kinetics of bilayer formation from vesicles and the characterization of structural changes have been investigated by time-resolved neutron reflectivity ${ }^{52,81}$. But these studies were carried out with adapted reflectometers and under appropriate conditions where adsorption was favoured. In our case, the time required to achieve equilibrium was defined from QCM-D experiments and used for neutron reflectivity experiments to ensure that the equilibrium state was reached. 
The technique is based on the fact that neutrons are reflected at each interface defined by a change of neutron refractive index $\left(n_{N}\right)$, which depends on the neutron scattering length density. The neutron refractive index of a non-adsorbing material is given by:

$$
n_{N}=1-\frac{\lambda^{2} \rho_{N}}{2 \pi}
$$

where $\rho_{N}$ is its neutron scattering length density defined as:

$$
\rho_{N}=\frac{\sum_{i} n_{i} b_{i}}{v_{M}}
$$

$v_{M}$ is the molecular volume and $n_{i}$ and $b_{i}$ are respectively the number and the coherent scattering length of atoms of type $i$ of the investigated molecule.

During the experiments, a macroscopic and molecularly flat surface was enlightened by a polychromatic beam of neutrons and the intensity of the reflected radiation was measured as a function of the neutron wavelength. In specular reflectivity, the angle $(\theta)$ of the incident beam is equal to the angle of the reflected beam. The reflectivity $R$, defined as the reflected intensity normalized by the incident intensity, is then represented as a function of the scattering vector $Q$, normal to the reflecting surface:

$$
Q=\frac{4 \pi \sin \theta}{\lambda}
$$

with $\lambda$ being the incident neutron wavelength and $\theta$ the angle of the reflected beam.

Adsorption measurements were done on a silicon wafer with a native amorphous silicon oxide layer. Measurements were made at two incident angles $\left(0.93^{\circ}\right.$ and $\left.2^{\circ}\right)$. The combination of wavelength (2-28 $\AA$ ) and incident angles gave a total $Q$ range varying from 0.008 to $0.15 \AA^{-1}$. Under this configuration, we observed a total reflection plateau. This plateau was used for the normalization of the reflectivity curves, but more importantly the total reflection edge is a function of the sample scattering length density and thus of the composition of the adsorbed layer. The 
reflectivity profile provided information on the structure of the adsorbed layer (thickness, structure and chemical composition).

A more detailed description of the technique can be found in the literature ${ }^{82}$.

\section{Calculation of the neutron scattering length densities}

The neutron scattering length densities of the investigated materials, $\rho_{N}$, have been calculated using equation ( 5 ). $b_{i}$ values are tabulated and $v_{M}$ is defined as:

$$
v_{M}=\frac{M}{d N a}
$$

where $M$ and $d$ are respectively the molar mass and the density of the part of the molecule being considered. $N a$ is the Avogadro's number. The calculated $\rho_{N}$ values presented in Table 2 are in accordance with those given in the literature for hydrogenated $\mathrm{AOT}^{27,50} . d_{\text {head }}$ and $d_{\text {tail }}$ were chosen according to the literature ${ }^{50}$.

Table 2 : Neutron Scattering Length Density of the materials used in this study

\begin{tabular}{|l|l|l|}
\hline Molecule & Formula & $\rho_{N}\left(\mathrm{x}^{-10} \mathrm{~cm}^{-2}\right)$ \\
\hline Silicon & $\mathrm{Si}$ & 2.07 \\
\hline Silicon oxide & $\mathrm{SiO}_{2}$ & 3.40 \\
\hline Heavy water & $\mathrm{D}_{2} \mathrm{O}$ & 6.4 \\
\hline Hydrogenated NaAOT & $\mathrm{C}_{20} \mathrm{H}_{37} \mathrm{NaO}_{7} \mathrm{~S}$ & 0.64 \\
\hline NaAOT tail (x2) & $\mathrm{C}_{8} \mathrm{H}_{15}$ & -0.14 \\
\hline NaAOT head & $\mathrm{C}_{4} \mathrm{H}_{7} \mathrm{NaO}_{7} \mathrm{~S}$ & 2.03 \\
\hline
\end{tabular}

\section{Cleaning procedure}

The cleaning procedure used for the silica wafer was the same as the one used by Lind et $a l .35,37$. Wafers were placed in a piranha mixture $\mathrm{H}_{2} \mathrm{O}_{2}, 30 \% / \mathrm{H}_{2} \mathrm{SO}_{4}, 96 \%(0.595: 0.405 \mathrm{in} \% \mathrm{v})$ at room 
temperature for $45 \mathrm{~min}$ and then intensively rinsed with pure water resulting in the formation of a nanometric oxide layer.

\section{Silicon oxide layer characterization}

For each $\mathrm{pH}$, the oxide layer has been characterized with reflectivity data obtained for the bare silicon wafer in contact with a $\mathrm{D}_{2} \mathrm{O}$ brine solution. Characteristics of the silicon oxide layers (scattering length density $\rho_{N}$, thickness $d$ and roughness $\sigma$ ) are presented in Table 3 .

Table 3: Characterization of the oxide layer formed on the silicon wafers used in neutron reflectivity experiments

\begin{tabular}{|l|l|l|l|}
\hline Wafer used for the & $\rho_{N} \times 10^{-10}\left[\mathrm{~cm}^{-2}\right]$ & $d[\mathrm{~nm}]$ & $\sigma[\mathrm{nm}]$ \\
\hline Acidic $\mathrm{pH}$ & 3.41 & 2.0 & 0.5 \\
\hline Neutral $\mathrm{pH}$ & 3.41 & 2.5 & 0.5 \\
\hline Basic $\mathrm{pH}$ & 3.41 & 2.0 & 0.8 \\
\hline
\end{tabular}

\section{Analysis of the experimental data}

Neutron specular reflectivity profiles were measured for hydrogenated AOT in $\mathrm{D}_{2} \mathrm{O}$ brine at different $\mathrm{pH}$ values. Experimental profiles were analyzed using the optical matrix method ${ }^{82}$. In this approach, the adsorbed layer is divided into a specific number of layers, where each one is characterized by its neutron scattering length density $\rho_{N}$, thickness $d$ and roughness $\sigma$. The calculated reflectivity profiles for different models describing the structure of the adsorbed layer were compared to the experimental data. Parameters of the models $\left(\rho_{N}, d\right.$ and $\left.\sigma\right)$ were varied until the best fit between calculated and experimental data was achieved.

\section{Results}

\section{QCM-D experiments}

Figure 3 shows shifts in frequency $\left(\Delta f_{n} / n\right)$ and dissipation $\left(\Delta D_{n} / n\right)$ for the three $\mathrm{pH}$ values. QCM-D experiments are relevant as they provide the adsorption kinetics revealing the existence 
of different structural intermediates and also different equilibrium structures as a function of the $\mathrm{pH}$. Even if the details of these structures (as well as their morphology, mechanical properties and chemical composition) are not directly accessible with QCM-D, it is possible to make some assumptions as for example on their softness. The assumptions made in the following motivated by previous works on the adsorption of phospholipidic vesicles ${ }^{35,40,49,83}$ are based on the analysis of the overtones' dependence of the QCM-D curves. Indeed, phospholipids are amphiphilic molecules composed of a hydrophilic head group (most of the time a negatively charged phosphate group) and two hydrophobic tails. AOT is a double tailed surfactant and we consider its behavior being similar to that of phospholipids. The assumptions made allowed us then the prediction and justification of the models proposed to interpret neutron reflectivity experiments

For all the $\mathrm{pH}$ values, after the injection of the surfactant solution, we note an initial rapid decrease of $\Delta f_{n} / n$, mainly related to surfactant adsorption (1) on Figure 3) followed by a slow increase related to the structuration of the adsorbed layer (2) until the equilibrium state is reached (3). The end times (1) and (2) are given in Table 4.

Table 4: Comparison of the different times needed to adsorb (end time (1)) and to reach equilibrium (end time (2))

\begin{tabular}{|l|l|l|l|}
\hline & Acidic $\mathrm{pH}$ & Neutral $\mathrm{pH}$ & Basic $\mathrm{pH}$ \\
\hline End time (1) [h] & 0.12 & 0.20 & 0.19 \\
\hline End time (2) [h] & 0.85 & 1.5 & 1.90 \\
\hline
\end{tabular}

The end time (2) was defined as the standard deviation was lower than 0.5 (which means a variation of $\Delta f_{3} / 3$ during 30 minutes lower than $0.5 \mathrm{~Hz}$ ) according to Thavorn et al. ${ }^{80}$ paper.

Desorption kinetics can predict the interaction strength between the adsorbed layer and the surface. For all investigated $\mathrm{pH}$, the adsorption is completely reversible and surfactant desorption 
(4) occurs rapidly (in one step), suggesting weak linkage between the surfactant layer and the surface.

The observed adsorption kinetics are related in a specific way to different degrees of interactions. Kinetics of structural rearrangements (2) are always long compared to the initial adsorption kinetics (1)). Additionally, the curves shape corresponds only partially to the typical results shown in the literature ${ }^{47}$ (Figure 1). Indeed, we observe for the three $\mathrm{pH}$ values a step related to the rearrangement of the adsorbed layer. However, the dissipation curves are very different. Thus, step (2) does not necessarily correspond to the formation of a bilayer. Consequently, a thorough investigation of the curves will be presented in the following.

\section{Acidic conditions: $\mathrm{pH} \sim 1.5$}

At this $\mathrm{pH}$, silica is supposed to be positively charged $\left(\mathrm{PZC} \sim 2^{52}\right)$. Frequency (Figure $3 \mathrm{a}$ ) and dissipation (Figure 3b) shifts demonstrate a two-phase process similar to that observed in the literature (Figure 1A $)^{47}$. Consequently, as dissipations are negligible at equilibrium state $\left(\Delta D_{n} / n\right.$ in (3) $<2 \times 10^{-6}$ ), we assume the formation of a rigid bilayer following the rupture of initially adsorbed vesicles.

However, the frequency shifts measured at equilibrium (3) do not perfectly overlay and are higher than those expected for an AOT rigid bilayer ${ }^{80}$. As the adsorbed layer is supposed to be rigid ( $\Delta D_{n} / n<2 \times 10^{-6}$ in (3)), these small deviations may be due to a small quantity of water trapped in the adsorbed layer (formation of a non-homogeneous bilayer with interpenetrated or tilted surfactant) only poorly influencing its rigidity. Also, the presence of a thin water layer between the silica surface and the surfactant layer, being too small to dissipate energy, might influence the frequency curves. Indeed, as the desorption is fast, the layer is not strongly attached to the surface. 
Moreover, we suppose that the discontinuity in the QCM-D curves around $0.35 \mathrm{~h}$ corresponds to the end of the vesicles fusion step and the beginning of their rupture. Kinetics of (2) are slow ( $\sim 10 \mathrm{~min}$ is usually observed in the literature) as the environmental conditions are not optimal, although rupture is promoted by $\mathrm{pH}$ lowering. Slow kinetics can be explained either by partial hydrophobicity of the silica surface (see Methods section: the silica surface used in QCM-D experiments is assumed to be slightly hydrophilic as there are $\sim 1.7 \mathrm{OH} / \mathrm{nm}^{2}$ ), by the screening of attractive interactions due to salt addition or by the fact that AOT is mainly in a non-dissociated form $\left(\mathrm{pH}<\mathrm{pKa}\right.$ of AOT $\sim 2.84^{84-86}$ ), promoting the fusion of vesicles and not their rupture. Indeed, rupture may be principally induced by attractive electrostatic interactions between vesicles and the solid surface.

\section{Intermediate conditions: $\mathrm{pH} \sim 6$}

In this case, the silica surface is supposed to be negatively charged as it is the case for the AOT vesicles. Compared to the acidic $\mathrm{pH}$, the structural rearrangements take more time due to lower vesicle/silica interactions. At the equilibrium state (3), frequency shifts are overtone dependent and dissipations are high. Thus, we suggested the adsorption of a soft layer composed of flexible aggregates such as vesicles. However, we did not observe a monotonically growing signal as it is the case for the adsorption of a close-packed layer of intact vesicles (see Figure 1B) ${ }^{47}$. The increase of $\Delta f_{n} / n$ observed in (2) might be explained by water release during the rearrangement step that may be due to flattening of vesicles or isolated vesicle rupture leading to the formation of an incomplete bilayer. Additionally, the fact that dissipation shifts are relatively independent of the overtone in step (3) (but still high as $\Delta D_{n} / n>>2 \times 10^{-6}$ ) suggests the formation of a more rigid and compact structure than in (2). This goes in accordance with the possibility of vesicle flattening. In 
fact, variations in dissipation are mainly due to the change in conformation, composition, rigidity and hydration of the adsorbed layer ${ }^{46,62,62,73}$.

We indicate that the investigated AOT/brine system only slightly adsorbs on silica below the CVC (see Figure S6 and Figure S7). The QCM-D curves are significantly different than those obtained at 2.7CVC (see Figure S8). A sharp increase in the initial adsorption rate at 2.7CVC is observed. As proposed by Velegol et $a l .{ }^{11}$, the difference of adsorption rates between $0.7 \mathrm{CVC}$ and 2.7CVC can be attributed to different adsorption mechanisms. We suppose the adsorption of monomers below the CVC and of vesicles above the CVC, in accordance with the assumption previously made. Indeed, if monomers were directly adsorbing at $2.7 \mathrm{CVC}$, the curves would be monotonic as those obtained for the adsorption of AOT on alumina (see Figure S9).

We therefore supposed the adsorption of a soft layer poorly linked to the substrate that is mainly composed of flattened AOT vesicles.

\section{Basic conditions: $\mathrm{pH} \sim 9$}

The change in frequency (Figure 3e) is less for the basic $\mathrm{pH}$ compared to the neutral one. This observation is consistent with the idea of less vesicle adsorption due to weaker interactions with the silica surface. However, the dissipations (Figure 3f) are higher for the high $\mathrm{pH}$. This reverse trend may be due to the increased softness of the adsorbed layer and to the poor linkage with the silica surface contributing to a higher deformation of the adsorbed layer causing more dissipation. At equilibrium (3), overtone responses of frequency and dissipation are more disordered and separated compared to the neutral $\mathrm{pH}$, providing an evidence for the formation of a softer adsorbed layer. As for the neutral conditions, we suggest the adsorption of a non-rigid layer composed of vesicles.

\section{Conclusion on the QCM-D results}


Figure 4 shows the overtone dependence of the frequency shifts that are generally interpreted in terms of softness of the adsorbed layer. Johannsmann et $a l .^{75}$ also suggested that this overtone dependence can be caused by hydrodynamic contributions. The more the contact zone can undergo oscillatory deformation, the larger the overtone dependence of $\Delta f_{n} / n$ is. As observed in Figure 4, this dependence is more pronounced for the higher $\mathrm{pH}$. We therefore suppose that the adsorbed layer is the softer at basic $\mathrm{pH}$ with a very reduced contact zone. This comment is in accordance with assumptions previously made. We have shown that interactions between surfactants and the silica surface at basic $\mathrm{pH}$ are not favourable and poorly attractive, thus flushing the surface with solvent easily removes the surfactants from the surface.

In conclusion, flexible or rigid aggregates are not sensed by the quartz in the same way. In the case of the acidic $\mathrm{pH}$, the adsorbed layer is rigid, and the frequency variations can be directly interpreted as an adsorbed mass contribution. The Sauerbrey model can be used to calculate the adsorbed quantity: $531 \mathrm{ng} / \mathrm{cm}^{2}$. Assuming a layer density of $1.1 \mathrm{~g} / \mathrm{cm}^{3}$ (as in Thavorn et $a l^{80}$ ), the thickness of the adsorbed layer is estimated to be $4.8 \mathrm{~nm}$. For the neutral $\mathrm{pH}$, the adsorbed layer is soft. The non-negligible amount of water trapped in the adsorbed layer makes the frequency variations different (lower) than expected as the "softness" of the layer significantly influences the oscillation of the quartz. This comment explains the 1.8 difference in $\Delta f_{n} / n$ between acidic and neutral $\mathrm{pH}$. However, quantitative information on the soft adsorbed layer can be obtained using the Kelvin-Voigt model ${ }^{73,87}$. Using this model, the thickness of the adsorbed layer at intermediate $\mathrm{pH}$ is estimated as $8.5 \mathrm{~nm}$ (details on the Kelvin-Voigt fitting are presented in the Supporting Information). For basic $\mathrm{pH}$, the adsorbed layer is too heterogeneous to be modelled with the Kelvin-Voigt model. The estimated thicknesses for acidic and neutral $\mathrm{pH}$ will be compared to those found by neutron reflectivity experiments in the following. 


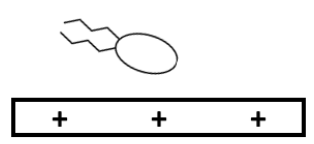

Acidic conditions

pH 1.5

a)

a)
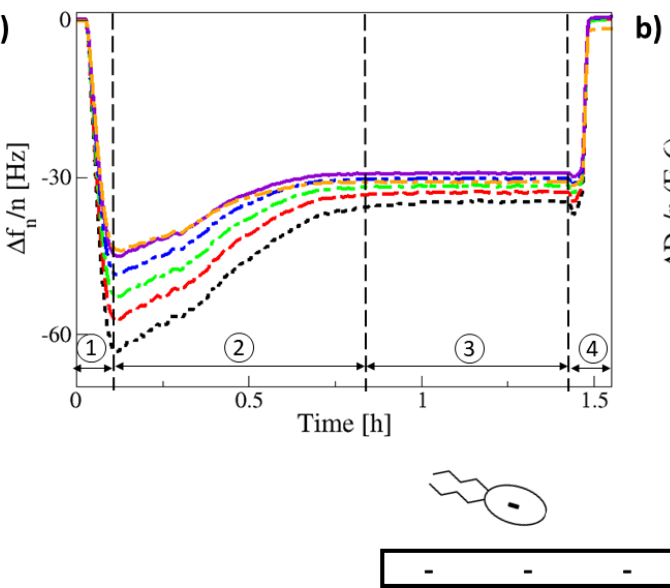

c)
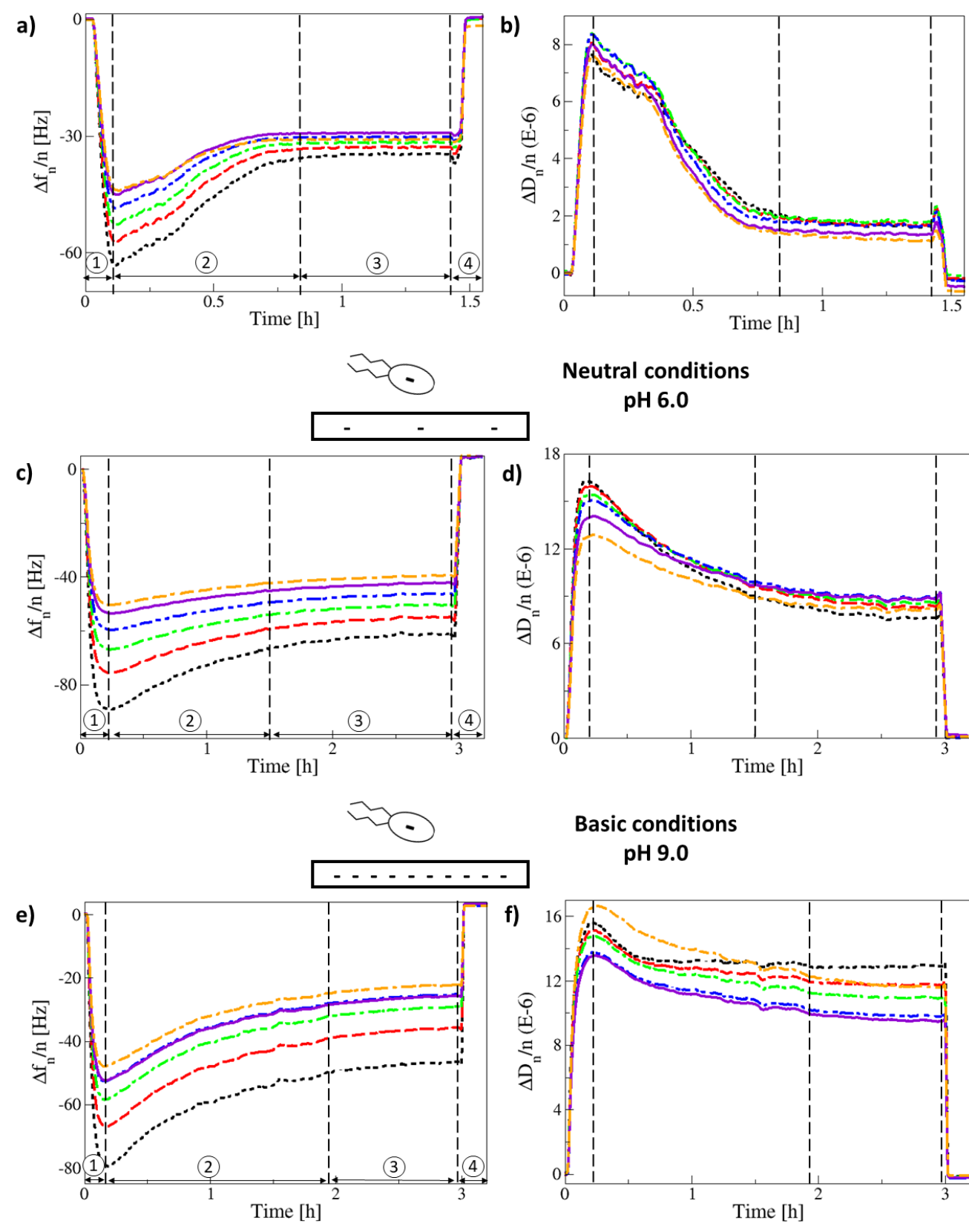

Neutral conditions pH 6.0

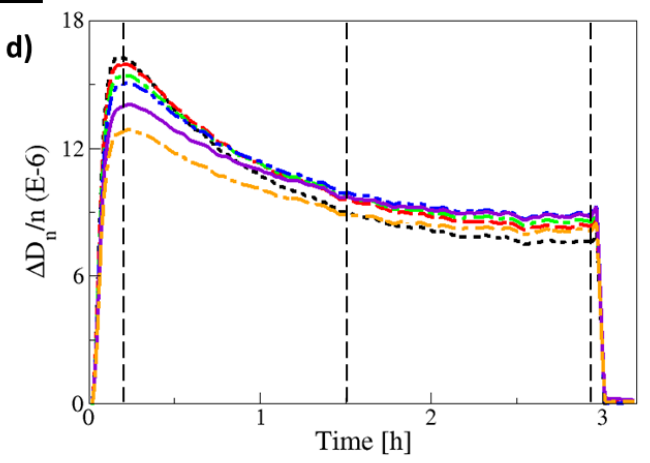

Basic conditions $\mathrm{pH} 9.0$

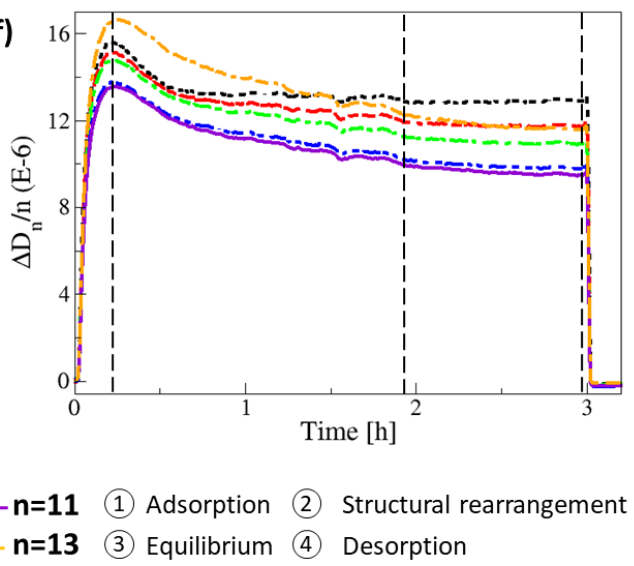

Figure 3: Normalized frequency and dissipation shifts versus time at different overtones during the adsorption of AOT $(2.7 \mathrm{CVC}=0.24 \mathrm{~g} / \mathrm{L})$ in brine $\mathrm{NaCl}(15 \mathrm{~g} / \mathrm{L})$ on silica at $20^{\circ} \mathrm{C}(\mathrm{a}, \mathrm{b})$ for acidic $\mathrm{pH}(\sim 1.5)(\mathrm{c}, \mathrm{d})$, intermediate $\mathrm{pH}(\sim 6)(\mathrm{e}, \mathrm{f})$ and basic $\mathrm{pH}(\sim 9)$. In step (4), the data goes higher than the initial values for the acidic and basic $\mathrm{pH}$ but this increase is considered negligible compared to the large $\Delta \boldsymbol{f}_{\boldsymbol{n}} / \boldsymbol{n}$ and $\Delta \boldsymbol{D}_{\boldsymbol{n}} / \boldsymbol{n}$ obtained in others steps. 


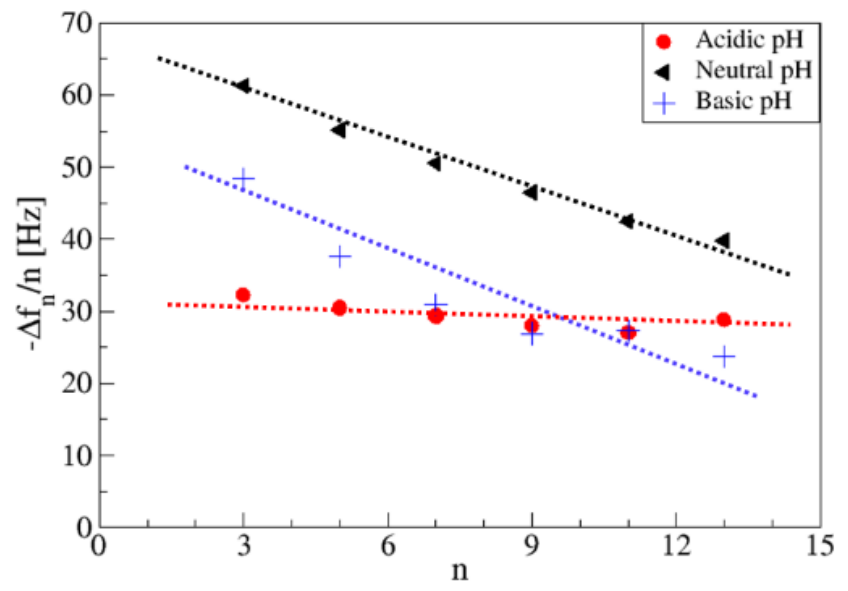

Figure 4: Normalized frequency shift, $\Delta \boldsymbol{f}_{\boldsymbol{n}} / \boldsymbol{n}$, versus overtone order, $\boldsymbol{n}$, for the three-pH investigated.

\section{Neutron reflectivity}

Neutron reflectivity data obtained for the bare silicon wafer in contact with brine and with the AOT/brine solution at different $\mathrm{pH}$ are presented in Figure 5. Significantly different profiles are observed providing an evidence of the existence of an adsorbed layer for all $\mathrm{pH}$ values. The best fits to the experimental data are presented in Figure 6 and also the principal parameters of the models used. In the models, each layer is characterized by an average neutron scattering length density $\rho_{N}$. This $\rho_{N}$ can also be written as:

$$
\rho_{N}=\rho_{A O T}(1-\varphi)+\rho_{D_{2} O} \varphi
$$

with $\rho_{A O T}$ being the scattering length density of the AOT surfactant (or the part of the AOT monomer being highlighted as for example the hydrophilic or hydrophobic parts), $\rho_{D_{2} O}$ the scattering length density of $\mathrm{D}_{2} \mathrm{O}$ and $\varphi$ the water volume fraction. $\rho$ values are chosen according to the Table 2. All $\varphi$ values are coherent with the assumptions made. 


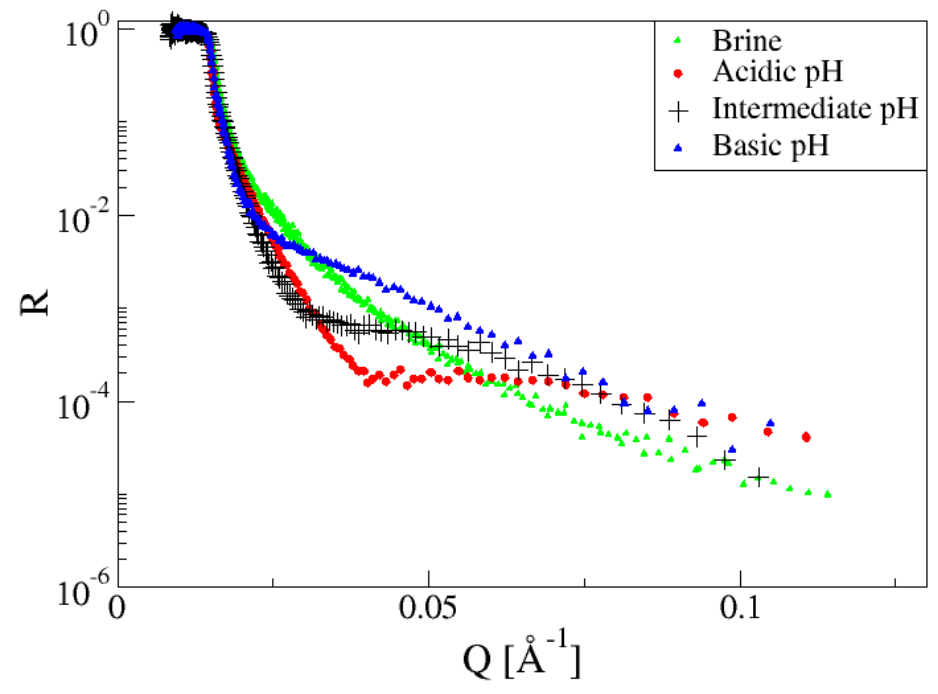

Figure 5: Reflectivity profiles of the bare silicon wafer (in contact with brine) and AOT surfactant in $\mathrm{D}_{2} \mathrm{O}$ brine at the three-pH investigated.

\section{Acidic conditions: $\mathrm{pH} \sim \mathbf{1 . 5}$}

The reflectivity profile and the corresponding fit are shown in Figure 6a. In the model, the bilayer structure is described by means of three layers in order to separate the contributions from the hydrophilic (H1 and $\mathrm{H} 2)$ and hydrophobic (T) parts. AOT forms a $4.4 \mathrm{~nm}$ bilayer separated from the surface by a $0.7 \mathrm{~nm}$ hydration layer. In the literature, a thin water layer of 1-2 $\mathrm{nm}$ thickness between the solid substrate and the adsorbed bilayer was frequently reported ${ }^{30,43}$. It can be specified that the hydrophobic thin layer $(\mathrm{T})$ is not representative of the hydrophobic part of the surfactant monomer but rather characterizes a thin layer containing only hydrophobic tail parts. This is due to the fact that the bilayer is rather disordered, as shown by elevated roughness $\sigma$. It might be possible that AOT monomers are interdigitated and/or tilted at the surface.

Similar data were observed in the literature: NaAOT was found to adsorb as a bilayer of $3.3 \mathrm{~nm}$ and $2.3 \mathrm{~nm}$ in the absence and presence of salt on sapphire ${ }^{50}$ or as a bilayer of $3.5 \mathrm{~nm}$ on calcite ${ }^{51}$. CaAOT forms a bilayer of $3.5 \mathrm{~nm}$ on silica ${ }^{27}$. The higher thickness of the AOT bilayer measured in our case may be explained by the formation of a none perfectly close-packed bilayer. The AOT 
bilayer was supposed to be more disorganized than the examples in previous studies because of the $\mathrm{pH}$ chosen close to the silica PZC.

Thus, neutron reflectivity experiments demonstrated that AOT may form a bilayer on silica even in non-optimal conditions. The estimated thickness is in accordance with the value found by QCMD experiments $(4.8 \mathrm{~nm})$. The quality of the neutron reflectivity fit being good, the combination of QCM-D and neutron reflectivity experiments is sufficient to confirm the formation of a bilayer under acidic conditions so that a second contrast measurement does not seem necessary.

\section{Intermediate conditions: $\mathrm{pH} \sim 6$}

Results for intermediate $\mathrm{pH}$ are given in Figure 6b: the large oscillation in the reflectivity profile demonstrates the formation of a thick hydrated layer. Several fits (bilayers, water layer + bilayer, bilayer + co-adsorbed vesicles...) have been tested and we only present the best fit. In order to provide the best fit to the experimental data, we constructed a complex structural model divided into seven layers in order to describe an adsorbed layer composed of vesicles. Figure $6 \mathrm{~b}$ shows the meaning of each layer and gives dimension $d$ and water content $\varphi$ of each layer. A 7-layer model was necessary to obtain a good fit in the entire investigated Q-range. A 3-layers model only allows good fitting up to $\mathrm{Q}=0.09 \AA^{-1}$.

Bilayer B2 has the same dimension as the bilayer of bulk vesicles characterized by SAXS experiments ${ }^{68}$. Moreover, both bilayers (B1 and B2) have the same water volume fraction. The total thickness of the adsorbed layer $(9.2 \mathrm{~nm})$ is smaller than the vesicle diameter $(14 \mathrm{~nm})$ characterized with DLS measurements ${ }^{68}$ suggesting the flattening of vesicles at the surface. Thus, at intermediate $\mathrm{pH}$, we assumed the formation of a layer composed of flattened vesicles, consistent with QCM-D estimations ( $8.5 \mathrm{~nm}$ found with the Kelvin Voigt model). Vesicle flattening at the solid surface has already been observed in the presence of interaction forces (as for example Van 
der Waals ones) that were not strong enough to induce vesicle rupture ${ }^{34,88}$. Experimental data at another contrast and the corresponding fit are presented in the Supporting Information.

\section{Basic conditions: $\mathbf{p H} \sim 9$}

Data obtained are presented in Figure 6c. Due to the increased number of anionic silanol groups on silica at higher $\mathrm{pH}$, interactions between AOT and silica are extremely weak.

The beginning of the small oscillation gives a thickness of about $12 \mathrm{~nm}$ that is in accordance with the vesicular size found from DLS. Moreover, the oscillation is not as well defined as it is the case for the neutral $\mathrm{pH}$, which can be interpreted by the presence of a disorganised and poorly contrasted adsorbed layer with a small number of surfactant molecules.

As the structure of the adsorbed layer is probably very heterogeneous and disordered, it is difficult to find a convenient model. An attempt to model this system by means of three layers is proposed in Figure 6c. As it is challenging to find a convenient model, experimental data at another contrast would not allow us to prove the uniqueness of the solution.

\section{Conclusion on the neutron reflectivity results}

In conclusion, all the models reported in neutron reflectivity experiments are coherent with QCM-D predictions demonstrating the complementarity of both techniques. 
a)
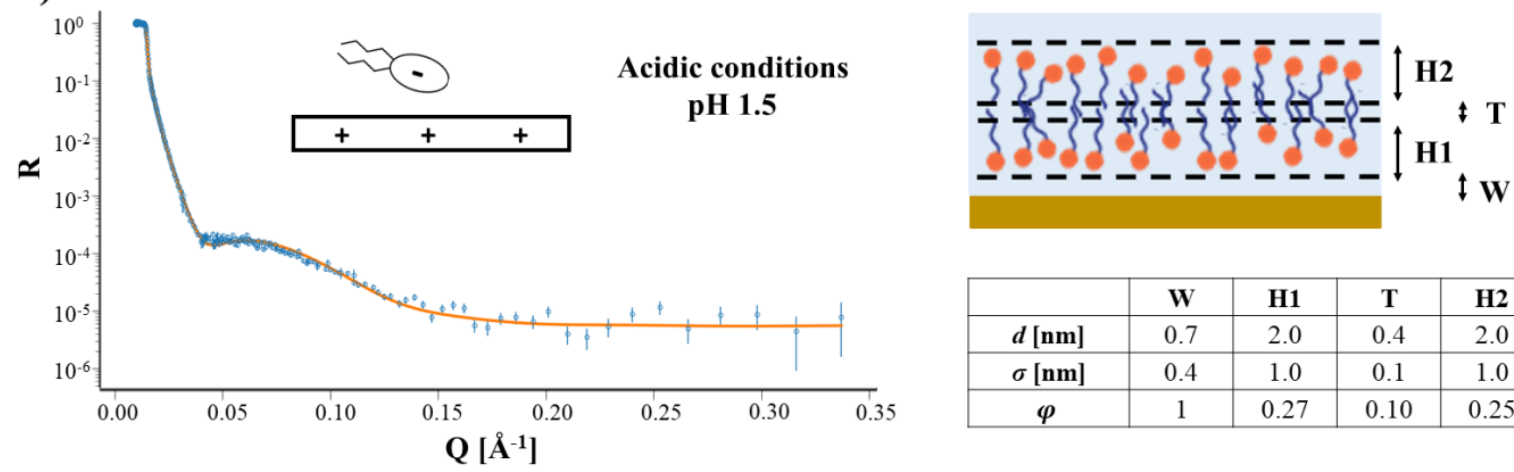

\begin{tabular}{|c|c|c|c|c|}
\hline & W & H1 & T & H2 \\
\hline $\boldsymbol{d}[\mathbf{n m}]$ & 0.7 & 2.0 & 0.4 & 2.0 \\
\hline$\sigma[\mathbf{n m}]$ & 0.4 & 1.0 & 0.1 & 1.0 \\
\hline $\boldsymbol{\varphi}$ & 1 & 0.27 & 0.10 & 0.25 \\
\hline
\end{tabular}

b)


\begin{tabular}{|c|c|c|c|c|c|c|c|}
\hline \multirow{2}{*}{} & \multicolumn{3}{|c|}{ B1 } & & \multicolumn{3}{|c|}{ B2 } \\
\cline { 2 - 8 } & H1 & T & H2 & C & H1 & T & H2 \\
\hline $\boldsymbol{d}[\mathbf{n m}]$ & 0.86 & 0.19 & 0.86 & 4.6 & 1.2 & 0.28 & 1.25 \\
\hline$\sigma[\mathbf{n m}]$ & 0.5 & 0.05 & 0.4 & 1.2 & 0.5 & 0.05 & 0.3 \\
\hline $\boldsymbol{\varphi}$ & 0.50 & 0.25 & 0.57 & 0.97 & 0.45 & 0.27 & 0.50 \\
\hline
\end{tabular}

c)

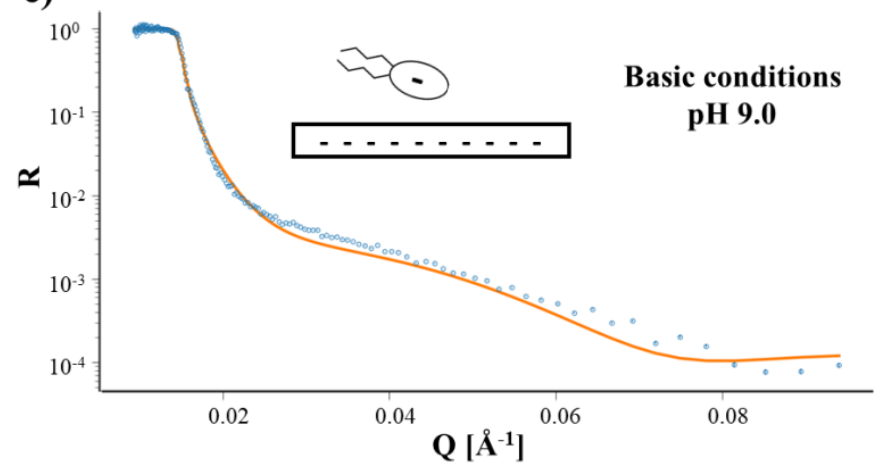

- Experimental data

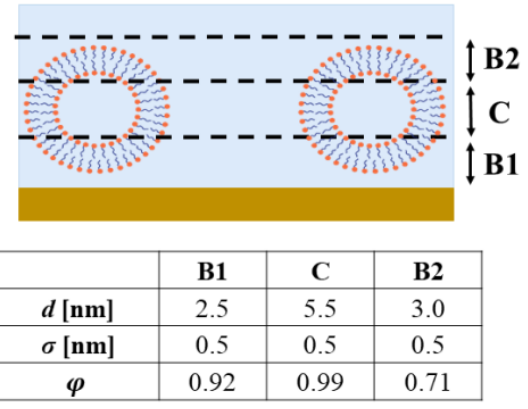

B1: bilayer of vesicles in contact with the surface

T: hydrophobic tail group

B2: bilayer of vesicles in contact with the bulk

$d$ : layer thickness

C: core of vesicles

$\varphi$ : water volume fraction

H1: hydrophilic head group in contact with the surface

$\sigma$ : layer roughness

H2: hydrophilic head group in contact with the bulk

Figure 6: Reflectivity profile, fit and schematic diagram of the AOT adsorbed layer a) acidic conditions b) intermediate conditions $\mathrm{c}$ ) basic conditions 


\section{Discussion}

Results demonstrated that adsorption occurred for all investigated $\mathrm{pH}$, although electrostatic repulsion was present. Adsorption layers have been characterized and all adsorption processes were reversible with desorption occurring rapidly providing a first evidence of weak interactions between AOT and silica. Thus, the key result of this work is a new step toward a better understanding of surfactant adsorption phenomena in an electrostatic repulsion environment.

QCM-D experiments have high temporal resolution allowing kinetics investigation even if structural information cannot be directly obtained. An interesting aspect of this work is the access to the long structural rearrangement kinetics. Neutron reflectivity provides information on the composition profile perpendicular to the surface at equilibrium state. The combination of both techniques was relevant and the modeling provided similar results. At acidic $\mathrm{pH}$, a rigid bilayer was formed. Non-monotonic QCM-D curves provided evidences that the bilayer structure was obtained from the rupture of initially adsorbed vesicles and not from individually adsorbed monomers. The long vesicle rupture kinetics demonstrated that the electrostatic attractive interactions were not as predominant as initially assumed. At intermediate and basic $\mathrm{pH}$, we highlighted the formation of a soft layer composed of vesicles, more or less densely packed depending on the $\mathrm{pH}$. The different kinetics measured are related to different intermediate states and degrees of interaction forces. In fact, in alkaline conditions, a more disorganized layer was formed because of the presence of increased electrostatic repulsions.

Previous studies ${ }^{89-92}$ related to the adsorption of various protein on silica have demonstrated the considerable effect of high ionic strength $(150 \mathrm{mM} \mathrm{NaCl})$ on the adsorption behavior. The overall result that can be highlighted is that salt induces promotion of the adsorption at initially electrostatically repulsive conditions and decreases adsorption at electrostatically attractive 
conditions. Poirier et $a l .{ }^{93}$ have explained the adsorption of SDBS on negatively charged quartz by the presence of sodium ions in the electrical double layer of the adsorbent as it was characterized as the main cationic ion. Kolev et $a .^{89}$ have shown that the addition of electrolytes leads to the binding of many counterions on the oppositely charged headgroups of surfactants adsorbed at the surface of an aqueous solution. This binding reduces considerably the magnitude of the net surface electric charge tending to increase the adsorbed surfactant density. In our study, the variation of $\mathrm{pH}$ at constant ionic strength causes significant change in the adsorption processes and clearly shows the competition between electrostatic and non-electrostatic interactions. At the intermediate and basic $\mathrm{pH}$, the repulsive interactions between AOT and silica are balanced by another interaction. The interplay between the two effects can explain the observed results.

The reduction of the high affinity character shown in acidic $\mathrm{pH}$ illustrated by the slow adsorption kinetics (Figure 3a) can be attributed to the screening of attractive electrostatic interactions between AOT and silica as the binding constant is lowered at high ionic strength. Indeed, if the adsorption was purely due to attractive electrostatic interactions, the kinetics would be instantaneous and monomer would directly adsorb (see the adsorption of AOT in brine on alumina: Figure S9). At the $\mathrm{NaCl}$ concentration investigated $(0.26 \mathrm{M})$, the Debye length is estimated to 0.6 $\mathrm{nm}\left(95 \mathrm{~nm}\right.$ with no salt considering an ionic strength of $\left.10^{-5} \mathrm{M}\right)$. This observation implies that electrostatic interactions take place at close proximity between AOT vesicles and silica. This calculated Debye length is of the order of magnitude of the water layer estimated by neutron reflectivity experiments $(0.7 \mathrm{~nm}$ in Figure 6a). Moreover, the partially inhibited adsorption can also be caused by the weakly positively charged silica surface (close to the PZC) and by the fact that the $\mathrm{pH}$ is below the $\mathrm{pKa}$ of AOT. 
Thus, $\mathrm{NaCl}$ addition tends to limit adsorption in the high affinity $\mathrm{pH}$ region and to increase adsorption at $\mathrm{pH}$ values where AOT is initially electrostatically repelled by silica (confirmed by Wang et $a l .{ }^{27}$ study and neutron reflectivity measurements presented in Figure S5). For the three $\mathrm{pH}$, we observe the attachment of vesicles to the surface instead of monomers. Thus, high ionic strength enhances adsorption as vesicles can complete closer packing on the surface because the repulsive vesicles/vesicles interactions in the adsorbed layer are reduced.

As explained in the Materials section, the AOT/brine system contains a small quantity of divalent cationic impurities. Previous studies have already reported contamination of the interface by AOT impurities ${ }^{67}$. Wang et $a l .{ }^{27}$ have demonstrated that it was possible to adsorb AOT onto anionic silica surface by adding divalent ions $\mathrm{Ca}^{2+}$ to the solution thanks to cation bridging formation. At $\mathrm{pH}$, as the silica is getting more negative, more anionic sites can interact with $\mathrm{Ca}^{2+}$ ions, thus the calcium adsorption is $\mathrm{pH}$ dependent. Our results do not show this trend: the adsorption at basic $\mathrm{pH}$ is significantly lower to that at the intermediate $\mathrm{pH}$. Moreover, Cross et $a l .{ }^{94}$ have shown that the only presence of $2 \times 10^{-6} \mathrm{~mol} / \mathrm{dm}^{3} \mathrm{CaCl}_{2}$ had a non-negligible effect on the adsorption of sodium dodecyl sulphate at the gas/liquid interface. However, they also highlighted the competition between sodium and calcium ions and showed that calcium non-adsorbs in the presence of 0.1 $\mathrm{mol} / \mathrm{dm}^{3} \mathrm{NaCl}$. Thus, the effect of a small quantity of divalent ions seems to be swamped when a sufficient concentration of $\mathrm{NaCl}$ is added. Thus, the divalent bridging due to impurities, even if it may interfere in the adsorption process, seems to be not sufficient to explain the observed adsorption phenomena. AOT should be adsorbed through the counterions present in the electrical double layer which is mainly composed of sodium ions. As we do not observe any adsorption of AOT without salt, the effect of salt is predominant in comparison to that of impurities. 
As it is reported in the literature, adsorption of anionic vesicles on silica and bilayer formation are promoted by elevated ionic strength and low $\mathrm{pH}$ values ${ }^{43}$. As stated in DLVO ("Derjaguin, Landau, Verwey, and Overbeek") theory ${ }^{95}$, attractive van der Waals interactions prevail at high ionic strength due to salt addition in comparison to repulsive electrostatic forces ${ }^{96}$. In fact, the electrostatic repulsion decreases with the increase of the electrolyte concentration because of a stronger screening effect, as the magnitude of the negative potential decreases near the surface ${ }^{21}$. The stabilization of anionic vesicles on a negatively charged silica surface at intermediate and basic $\mathrm{pH}$ can therefore be explained by the combination of several forces, particularly van der Waals interactions and the formation of hydrogen bonds between the sulfonate AOT head group and silanol groups ( $\mathrm{Si}-\mathrm{OH})$. This interpretation is supported by the following studies: Rapuano et $a l .{ }^{19}$ observed the adsorption of anionic phospholipid vesicles on silica at neutral $\mathrm{pH}$ and BessaiesBey et $a l .{ }^{18}$ the adsorption of negatively charged HPAM polymer on silica at elevated ionic strength and intermediate $\mathrm{pH}$. Both studies have explained the formation of the adsorbed layer in unfavorable conditions by the existence of multiple hydrogen bonds.

\section{Conclusion}

This paper provides new insight into the kinetics of vesicle adsorption and the structural rearrangements occurring during the adsorption of negatively charged vesicles on silica. We can highlight the existence of an adsorbed layer, whatever the conditions, whose softness varies considerably as a function of the $\mathrm{pH}$. The characterization of the adsorbed layer was possible thanks to the combination of the QCM-D with neutron reflectivity as both techniques provided complementary information and also similar model for the structure of the adsorbed layer at the equilibrium state. The acquisition of adsorption kinetics provided information on the strength of 
interactions between AOT vesicles and silica which allowed us to make assumptions on the adsorption mechanisms and interactions being involved.

The addition of salt to the solution promotes the adsorption of AOT on silica by favoring attractive van der Waals interactions in comparison to repulsive electrostatic ones, as no adsorption was measured without sodium chloride ${ }^{27}$. Moreover, we suggest that the presence of vesicular aggregates in solution has a considerable impact on the adsorption process in unfavorable conditions, which may not be possible with less flexible aggregates such as micelles. This work enables to highlight the importance of electrostatic interactions in the adsorption phenomena. 


\section{Supporting Information.}

Additional information for the adsorption of AOT on silica at the neutral $\mathrm{pH}$ are given: surface tension plots, modelling of the QCM-D data by the Kelvin-Voigt model, second contrast measurement for the neutron reflectivity experiment and adsorption results obtained under different conditions (without salt, below the CVC and adsorption on alumina surface).

\section{Corresponding Author}

* Christine DALMAZZONE: christine.dalmazzone@ifpen.fr

\section{Author Contributions}

The manuscript was written through contributions of all authors. All authors have given approval to the final version of the manuscript.

\section{Acknowledgment}

The authors thank the Laboratoire Léon Brillouin for beam time allocation. We also thank the anonymous reviewers for their careful reading of our study and their many constructive comments and suggestions.

\footnotetext{
Abbreviations

AOT, sodium bis(2-ethyl-1-hexyl)sulfosuccinate; EOR, enhanced oil recovery; QCM-D, quartz crystal microbalance with dissipation; PZC, point of zero charge; DLVO, Derjaguin, Landau, Verwey, and Overbeek.
} 


\section{References}

(1) Milton J. Rosen. Surfactants and Interfacial Phenomena, Third Edition; Wiley Interscience: New York, 2004.

(2) Yueying Gao, Jizhou Du and Tiren Gu. Hemimicelle Formation of Cationic Surfactants at the Silica Gel-Water Interface. J. Chem. SOC., Faraday Trans I 1987, 83 (8), 2671-2679.

(3) A. Andrzejewska, M. Drach and J. Narkiewicz-Michałek. Theoretical description of surfactant aggregation at the solid/liquid interface - comparative study. Annales universitatis Mariae Curie-Sklodowska (Maria Curie-Skłodowska University - UMCS) Lublin - Polonia 2006, VOL. LXI, 9 - SECTIO AA.

(4) Chen, Y. L.; Chen, S.; Frank, C.; Israelachvili, J. Molecular mechanisms and kinetics during the self-assembly of surfactant layers. Journal of Colloid and Interface Science 1992, 153 (1), 244-265.

(5) K. Esumi and M. Ueno. Structure-performance relationships in surfactants, 2nd ed., rev. and expanded.; Surfactant science series 112; Marcel Dekker: New York, 2003.

(6) Srinivas Manne, Hermann E. Gaub. Molecular Organization of Surfactants at Solid-Liquid Interfaces. Science 1995, 270.

(7) Fan, A.; Somasundaran, P.; Turro, N. J. Adsorption of Alkyltrimethylammonium Bromides on Negatively Charged Alumina. Langmuir 1997, 13 (3), 506-510.

(8) Gu, T.; Huang, Z. Thermodynamics of hemimicellization of cetyltrimethylammonium bromide at the silica gel/water interface. Colloids and Surfaces 1989, 40, 71-76.

(9) R. Atkin, V. S. J. Craig, E. J. Wanless and S. Biggs. Mechanism of cationic surfactant adsorption at the solid-aqueous interface. Advances in colloid and interface science 2003, 103 (3), 219-304. 
(10) R. Denoyel and J. Rouquerol. Thermodynamic (including Microcalorimetry) Study of the Adsorption of Nonionic and Anionic Surfactants onto Silica, Kaolin, and Alumina. Journal of Colloid and Interface Science 1991, Vol. 143 (No. 2).

(11) Velegol, S. B.; Fleming, B. D.; Biggs, S.; Wanless, E. J.; Tilton, R. D. Counterion Effects on Hexadecyltrimethylammonium Surfactant Adsorption and Self-Assembly on Silica. Langmuir 2000, 16 (6), 2548-2556.

(12) Scanner. Intermolecular and Surface Forces. In Intermolecular and Surface Forces, ACADEMIC PRESS; J. Israelachvili, Ed.; Elsevier, 1991; iii.

(13) Huang, J.-H.; Zeng, G.-M.; Zhou, C.-F.; Li, X.; Shi, L.-J.; He, S.-B. Adsorption of surfactant micelles and $\mathrm{Cd} 2+/ \mathrm{Zn} 2+$ in micellar-enhanced ultrafiltration. Journal of hazardous materials 2010, 183, 287-293.

(14) P. Somasundaran and L. Huang. Adsorption/aggregation of surfactants and their mixtures at solid-liquid interfaces. Advances in colloid and interface science 2000, 88 (1-2), 179-208. (15) P. Somasundaran and L. Zhang. Adsorption of surfactants on minerals for wettability control in improved oil recovery processes. Journal of Petroleum Science and Engineering 2006, $52(1-4), 198-212$.

(16) P. Somasundaran, T. W. Healy and D. W. Fuerstenau. The Aggregation of Colloidal Alumina Dispersions by Adsorbed Surfactant Ions. Journal of Colloid and Interface Science 1966, 22, 599--605.

(17) R. Zhang, P. S. Advances in adsorption of surfactants and their mixtures at solid/solution interfaces. Advances in colloid and interface science 2006, 123-126, 213-229.

(18) Bessaies-Bey, H.; Fusier, J.; Harrisson, S.; Destarac, M.; Jouenne, S.; Passade-Boupat, N.; Lequeux, F.; d'Espinose de Lacaillerie, J.-B.; Sanson, N. Impact of polyacrylamide adsorption on 
flow through porous siliceous materials: State of the art, discussion and industrial concern. Journal of Colloid and Interface Science 2018, 531, 693-704.

(19) Rapuano, R.; Carmona-Ribeiro, A. M. Physical Adsorption of Bilayer Membranes on Silica. Journal of Colloid and Interface Science 1997, 193 (1), 104-111.

(20) A. Bera, T. Kumar, K. Ojha and A. Mandal. Adsorption of surfactants on sand surface in enhanced oil recovery: Isotherms, kinetics and thermodynamic studies. Applied Surface Science 2013, 284, 87-99.

(21) P. Li and M. Ishiguro. Adsorption of anionic surfactant (sodium dodecyl sulfate) on silica. Soil Science and Plant Nutrition 2016, 62 (3), 223-229.

(22) D. M. Nevskaia, A. Guerrero-Ruiz and J. de D. Lopez-Gonzalez. Adsorption of Polyoxyethylenic Nonionic and Anionic Surfactants from Aqueous Solution: Effects Induced by the Addition of $\mathrm{NaCl}$ and $\mathrm{CaCl} 2$. Journal of Colloid and Interface Science 1998, 205.

(23) Paria, S.; Manohar, C.; Khilar, K. C. Kinetics of Adsorption of Anionic, Cationic, and Nonionic Surfactants. Ind. Eng. Chem. Res. 2005, 44, 3091-3098.

(24) Allen, F. J.; Griffin, L. R.; Alloway, R. M.; Gutfreund, P.; Lee, S. Y.; Truscott, C. L.; Welbourn, R. J. L.; Wood, M. H.; Clarke, S. M. An Anionic Surfactant on an Anionic Substrate: Monovalent Cation Binding. Langmuir 2017, 33, 7881-7888.

(25) Allen, F. J.; Truscott, C. L.; Gutfreund, P.; Welbourn, R. J. L.; Clarke, S. M. Potassium, Calcium, and Magnesium Bridging of AOT to Mica at Constant Ionic Strength. Langmuir 2019, $35,5753-5761$.

(26) David Pastré; Olivier Piétrement; Stéphane Fusil; Fabrice Landousy; Josette Jeusset; MarieOdile David; Loïc Hamon; Eric Le Cam; Alain Zozime. Adsorption of DNA to Mica Mediated 
by Divalent Counterions: A Theoretical and Experimental Study. Biophysical journal 2003, 85, $2507-2518$.

(27) X. Wang, S. Y. Lee, K. Miller, R. Welbourn, I. Stocker, S. Clarke, M. Casford, P.

Gutfreund and M. W. A. Skoda. Cation bridging studied by specular neutron reflection.

Langmuir 2013, 29 (18), 5520-5527.

(28) Lunkenheimer, K.; Miller, R. A criterion for judging the purity of adsorbed surfactant layers. Journal of Colloid and Interface Science 1987, 120, 176-183.

(29) S. W. An; J. R. Lu; and; R. K. Thomas. Apparent Anomalies in Surface Excesses

Determined from Neutron Reflection and the Gibbs Equation in Anionic Surfactants with Particular Reference to Perfluorooctanoates at the Air/Water Interface. Langmuir 1996, 12, $2446-2453$.

(30) Castellana, E. T.; Cremer, P. S. Solid supported lipid bilayers: From biophysical studies to sensor design. Surface Science Reports 2006, 61 (10), 429-444.

(31) Hardy, G. J.; Nayak, R.; Zauscher, S. Model cell membranes: Techniques to form complex biomimetic supported lipid bilayers via vesicle fusion. Current opinion in colloid \& interface science 2013, 18 (5), 448-458.

(32) Richter, R. P.; Bérat, R.; Brisson, A. R. Formation of solid-supported lipid bilayers: an integrated view. Langmuir 2006, 22 (8), 3497-3505.

(33) Johnson, J. M.; Ha, T.; Chu, S.; Boxer, S. G. Early Steps of Supported Bilayer Formation Probed by Single Vesicle Fluorescence Assays. Biophysical journal 2002, 83 (6), 3371-3379. (34) Reimhult, E.; Höök, F.; Kasemo, B. Intact Vesicle Adsorption and Supported Biomembrane Formation from Vesicles in Solution: Influence of Surface Chemistry, Vesicle Size, Temperature, and Osmotic Pressure. Langmuir 2003, 19 (5), 1681-1691. 
(35) Lind, T. K.; Cárdenas, M.; Wacklin, H. P. Formation of supported lipid bilayers by vesicle fusion: effect of deposition temperature. Langmuir 2014, 30 (25), 7259-7263.

(36) Cho, N.-J.; Frank, C. W.; Kasemo, B.; Höök, F. Quartz crystal microbalance with dissipation monitoring of supported lipid bilayers on various substrates. Nature protocols 2010, 5 (6), 1096-1106.

(37) Lind, T. K.; Wacklin, H.; Schiller, J.; Moulin, M.; Haertlein, M.; Pomorski, T. G.; Cárdenas, M. Formation and Characterization of Supported Lipid Bilayers Composed of Hydrogenated and Deuterated Escherichia coli Lipids. PloS one 2015, 10 (12), e0144671. (38) Merz, C.; Knoll, W.; Textor, M.; Reimhult, E. Formation of supported bacterial lipid membrane mimics. Biointerphases 2008, 3 (2), FA41.

(39) Nollert, P.; Kiefer, H.; Jähnig, F. Lipid vesicle adsorption versus formation of planar bilayers on solid surfaces. Biophysical journal 1995, 69 (4), 1447-1455.

(40) Cho, N.-J.; Frank, C. W.; Kasemo, B.; Höök, F. Quartz crystal microbalance with dissipation monitoring of supported lipid bilayers on various substrates. Nature protocols $\mathbf{2 0 1 0}, 5$ (6), 1096-1106.

(41) Jing, Y.; Trefna, H.; Persson, M.; Kasemo, B.; Svedhem, S. Formation of supported lipid bilayers on silica: relation to lipid phase transition temperature and liposome size. Soft Matter 2014, $10(1), 187-195$.

(42) Erik Reimhult, Fredrik Höök, and Bengt Kasemo. Vesicle adsorption on $\mathrm{SiO} 2$ and TiO2 : Dependence on vesicle size. The Journal of chemical physics 2002, 117, 7401-7404.

(43) Cremer, P. S.; Boxer, S. G. Formation and Spreading of Lipid Bilayers on Planar Glass Supports. J. Phys. Chem. B 1999, 103 (13), 2554-2559. 
(44) Hook, F.; Rodahl, M.; Brzezinski, P.; Kasemo, B. Energy Dissipation Kinetics for Protein and Antibody-Antigen Adsorption under Shear Oscillation on a Quartz Crystal Microbalance. Langmuir 1998, 14 (4), 729-734.

(45) M. Rodahl, F. Hook and B. Kasemo. QCM Operation in Liquids: An Explanation of QCM Operation in Liquids: An Explanation of Measured Variations in Frequency and Q Factor with Liquid Conductivity. Anal. Chem 1996, 68, 2219-2227.

(46) Hook, F.; Kasemo, B.; Nylander, T.; Fant, C.; Sott, K.; Elwing H. Variations in Coupled Water, Viscoelastic Properties, and Film Thickness of a Mefp-1 Protein Film during Adsorption and Cross-Linking: A Quartz Crystal Microbalance with Dissipation Monitoring, Ellipsometry, and Surface Plasmon Resonance Study. Anal. Chem. 2001, 73 (24), 5796-5804.

(47) Hardy, G. J.; Nayak, R.; Alam, S. M.; Shapter, J. G.; Heinrich, F.; Zauscher, S. Biomimetic supported lipid bilayers with high cholesterol content formed by $\alpha$-helical peptide-induced vesicle fusion. Journal of materials chemistry 2012, 22 (37), 19506-19513.

(48) Richter, R. P.; Brisson, A. R. Following the formation of supported lipid bilayers on mica: a study combining AFM, QCM-D, and ellipsometry. Biophysical journal 2005, 88 (5), 34223433.

(49) Lind, T. K.; Cárdenas, M. Understanding the formation of supported lipid bilayers via vesicle fusion-A case that exemplifies the need for the complementary method approach (Review). Biointerphases 2016, 11 (2), 20801.

(50) Hellsing, M. S.; Rennie, A. R.; Hughes, A. V. Effect of concentration and addition of ions on the adsorption of aerosol-OT to sapphire. Langmuir 2010, 26 (18), 14567-14573. 
(51) Stocker, I. N.; Miller, K. L.; Welbourn, R. J. L.; Clarke, S. M.; Collins, I. R.; Kinane, C.;

Gutfreund, P. Adsorption of Aerosol-OT at the calcite/water interface--comparison of the sodium and calcium salts. Journal of Colloid and Interface Science 2014, 418, 140-146.

(52) Gutberlet, T.; Steitz, R.; Fragneto, G.; Klösgen, B. Phospholipid bilayer formation at a bare Si surface: A time-resolved neutron reflectivity study. J. Phys.: Condens. Matter 2004, 16 (26), S2469-S2476.

(53) Biswas; Chattoraj. Kinetics of Adsorption of Cationic Surfactants at Silica-Water Interface. Journal of Colloid and Interface Science 1998, 205, 12-20.

(54) Peyre, V.; Lakhal, A.; Fronteau, A.; Nzang-Emane, M.; Letellier, P. Kinetics and isotherms of adsorption of alkyldimethylamine oxide on a porous hydrophobic polymer: A thermodynamic approach to a Langmuir-like phenomenon. Colloids and Surfaces A: Physicochemical and Engineering Aspects 2006, 281, 261-270.

(55) Atkin, R.; Craig, V. S. J.; Biggs, S. Adsorption Kinetics and Structural Arrangements of Cationic Surfactants on Silica Surfaces. Langmuir 2000, 16, 9374-9380.

(56) Howard, S. C.; Craig, V. S. J. Very slow surfactant adsorption at the solid-liquid interface is due to long lived surface aggregates. Soft Matter 2009, 5, 3061.

(57) Ducker, W. A.; Wanless, E. J. Adsorption of Hexadecyltrimethylammonium Bromide to Mica: Nanometer-Scale Study of Binding-Site Competition Effects. Langmuir 1999, 15, 160168.

(58) Wanless, E. J.; Davey, T. W.; Ducker, W. A. Surface Aggregate Phase Transition. Langmuir 1997, 13, 4223-4228.

(59) Wanless, E. J.; Ducker, W. A. Organization of Sodium Dodecyl Sulfate at the Graphite-Solution Interface. J. Phys. Chem. 1996, 100, 3207-3214. 
(60) Pagac, E. S.; Prieve, D. C.; Tilton, R. D. Kinetics and Mechanism of Cationic Surfactant Adsorption and Coadsorption with Cationic Polyelectrolytes at the Silica-Water Interface.

Langmuir 1998, 14, 2333-2342.

(61) C. Gutig, B. P. Grady and A. Striolo. Experimental studies on the adsorption of two surfactants on solid-aqueous interfaces: adsorption isotherms and kinetics. Langmuir 2008, 24 (9), 4806-4816.

(62) S-X. Liu and J-T. Kim. Application of Kevin-Voigt Model in Quantifying Whey Protein Adsorption on Polyethersulfone Using QCM-D. Journal of the Association for Laboratory Automation 2009, 14 (4), 213-220.

(63) Fredrik Tiberg; Bengt Jonsson; Ji-an Tang and Bjorn Lindman. Ellipsometry Studies of the Self-Assembly of Nonionic Surfactants at the Silica-Water Interface: Equilibrium Aspects.

Langmuir 1994, 10, 2294-2300.

(64) Fredrik Tiberg; Bengt Jonsson; Ji-an Tang and Bjorn Lindman. Ellipsometry Studies of the Self-Assembly of Nonionic Surfactants at the Silica-Water Interface: Kinetic Aspects. Langmuir 1994, 10, 2294-2300.

(65) Levitz, P.; Korb, J. P.; Petit, D. Slow dynamics of embedded fluid in mesoscopic confining systems as probed by NMR relaxometry. The European physical journal. E, Soft matter 2003, $12,29-33$.

(66) Tummala, N. R.; Shi, L.; Striolo, A. Molecular dynamics simulations of surfactants at the silica-water interface: Anionic vs nonionic headgroups. Journal of Colloid and Interface Science 2011, 362, 135-143.

(67) Z. X. Li,J. R. Lu, and, and R. K. Thomas. Neutron Reflectivity Studies of the Adsorption of Aerosol-OT at the Air/Water Interface: The Surface Excess. Langmuir 1997, 13, 3681-3685. 
(68) Wolanin, J.; Barre, L.; Dalmazzone, C.; Bauer, D. A complete characterization of the structure of the vesicular phase in AOT — Brine system in the diluted region of the phase diagram. Colloids and Surfaces A: Physicochemical and Engineering Aspects 2018, 559, $218-$ 225.

(69) Ralph K. Iler. The chemistry of silica: Solubility, Polymerization, Colloid and Surface Properties, and Biochemistry; John Wiley and Sons, 1979.

(70) Sauerbrey G. Verwendung von Schwingquarzen zur Wagung dunner Schichten und zur Mikrowagung. Zeitschrift fiir Physik 1959, 155.

(71) Stalgren, J. J. R.; Eriksson, J.; Boschkova, K. A comparative study of surfactant adsorption on model surfaces using the quartz crystal microbalance and the ellipsometer. Journal of Colloid and Interface Science 2002, 253, 190-195.

(72) Matthew C. Dixon. Quartz Crystal Microbalance with Dissipation Monitoring: Enabling Real-Time Characterization of Biological Materials and Their Interactions. Journal of Biomolecular Techniques 2008, 19: 151-158.

(73) M. V. Voinova, M. Rodahl, M. Jonson and B. Kasemo. Viscoelastic Acoustic Response of Layered Polymer Films at Fluid-Solid Interfaces: Continuum Mechanics Approach. Physica Scripta 1999, Vol. 59, 391-396.

(74) T. Pauporté \& D. Lincot. Microbalance à cristal de quartz. TECHNIQUES DE L'INGÉNIEUR 2006.

(75) Johannsmann, D.; Reviakine, I.; Richter, R. P. Dissipation in films of adsorbed nanospheres studied by quartz crystal microbalance (QCM). Analytical chemistry 2009, 81 (19), 8167-8176. 
(76) M. Rodahl, F. Hook, A. Krozer, P. Brzezinski and B. Kasemo. Quartz crystal microbalance setup for frequency and Q-factor measurements in gaseous and liquid environments. Rev. Sci. Instrum. 1995, 7, 3924-3928.

(77) K. Keiji Kanazawa and Joseph G. Gordon II. Frequency of a Quartz Microbalance in Contact with Liquid. Anal. Chem. 1985, 57, 1770-1771.

(78) K. Keiji Kanazawa and Joseph G. Gordon II. The oscillation frequency of a quartz resonator in contact with liquid. Analytica Chimica Acta 1985, 175, 99-105.

(79) Zhuravlev, L. T. The surface chemistry of amorphous silica. Zhuravlev model. Colloids and Surfaces A: Physicochemical and Engineering Aspects 2000, 173 (1-3), 1-38.

(80) J. Thavorn, J. J. Hamon, B. Kitiyanan, A. Striolo and B. P. Grady. Competitive surfactant adsorption of AOT and Tween 20 on gold measured using a quartz crystal microbalance with dissipation. Langmuir 2014, 30 (37), 11031-11039.

(81) Koutsioubas, A.; Appavou, M.-S.; Lairez, D. Time-Resolved Neutron Reflectivity during Supported Membrane Formation by Vesicle Fusion. Langmuir 2017, 33, 10598-10605. (82) J Penfold and R K Thomas. The application of the specular reflection of neutrons to the study of surfaces and interfaces. J. Phys.: Condens. Matter 1990, 2, 1369-1412.

(83) Ralf Richter; Anneke Mukhopadhyay; Alain Brisson. Pathways of Lipid Vesicle Deposition on Solid Surfaces: A Combined QCM-D and AFM Study. Biophysical journal 2003, $85,3035-3047$.

(84) Fuda, E.; Jauregi, P.; Pyle, D. L. Recovery of lactoferrin and lactoperoxidase from sweet whey using colloidal gas aphrons (CGAs) generated from an anionic surfactant, AOT. Biotechnology progress 2004, 20 (2), 514-525. 
(85) Jauregi, P.; Gilmour, S.; Varley, J. Characterisation of colloidal gas aphrons for subsequent use for protein recovery. Chemical Engineering Journal 1997, 65 (1), 1-11.

(86) Marques, B. S.; Nucci, N. V.; Dodevski, I.; Wang, K. W. C.; Athanasoula, E. A.; Jorge, C.; Wand, A. J. Measurement and control of $\mathrm{pH}$ in the aqueous interior of reverse micelles. The journal of physical chemistry. B 2014, 118 (8), 2020-2031.

(87) T. Tammelin, J. Merta, L-S. Johansson and P. Stenius. Viscoelastic properties of cationic starch adsorbed on quartz studied by QCM-D. Langmuir : the ACS journal of surfaces and colloids 2004, 20, 10900-10909.

(88) Cho, N.-J.; Jackman, J. A.; Liu, M.; Frank, C. W. pH-driven assembly of various supported lipid platforms: a comparative study on silicon oxide and titanium oxide. Langmuir 2011, 27 (7), 3739-3748.

(89) Kolev, V. L.; Danov, K. D.; Kralchevsky, P. A.; Broze, G.; Mehreteab, A. Comparison of the van der Waals and Frumkin Adsorption Isotherms for Sodium Dodecyl Sulfate at Various Salt Concentrations. Langmuir 2002, 18, 9106-9109.

(90) Meissner, J.; Prause, A.; Bharti, B.; Findenegg, G. H. Characterization of protein adsorption onto silica nanoparticles: Influence of $\mathrm{pH}$ and ionic strength. Colloid and Polymer Science 2015, 293, 3381-3391.

(91) van der Veen, M.; Norde, W.; Stuart, M. C. Electrostatic interactions in protein adsorption probed by comparing lysozyme and succinylated lysozyme. Colloids and surfaces. B, Biointerfaces 2004, 35, 33-40.

(92) Takashi, N.; Tomoyuki, M.; Kaori, S.; Setsuo, S.; Masayuki, T.; Yoshima, A. Effect of pH and Addition of Salt on the Adsorption Behavior of Lysozyme on Gold, Silica, and Titania 
Surfaces Observed by Quartz Crystal Microbalance with Dissipation Monitoring. Dental

Materials Journal 2008, 27, 573-580.

(93) J.E. Poirier; J.M. Cases. Anionic surfactant adsorption onto silicate minerals The role of the cations. Colloids and Surfaces 1991, 55, 333-344.

(94) A. W. Cross; G. G. Jayson. The Effect of Small Quantities of Calcium on the Adsorption of Sodium Dodecyl Sulfate and Calcium at the Gas-Liquid Interface. JOURNAL OF COLLOID AND INTERFACE SCIENCE , 1994, 162, 45-51.

(95) J. Israelachvili, Ed. Intermolecular and Surface Forces, ACADEMIC PRESS; Elsevier, 1991.

(96) Li, Z. X.; Weller, A.; Thomas, R. K.; Rennie, A. R.; Webster, J. R. P.; Penfold, J.; Heenan, R. K.; Cubitt, R. Adsorption of the Lamellar Phase of Aerosol-OT at the Solid/Liquid and Air/Liquid Interfaces. J. Phys. Chem. B 1999, 103, 10800-10806. 
Table of Contents Graphic (TOC)

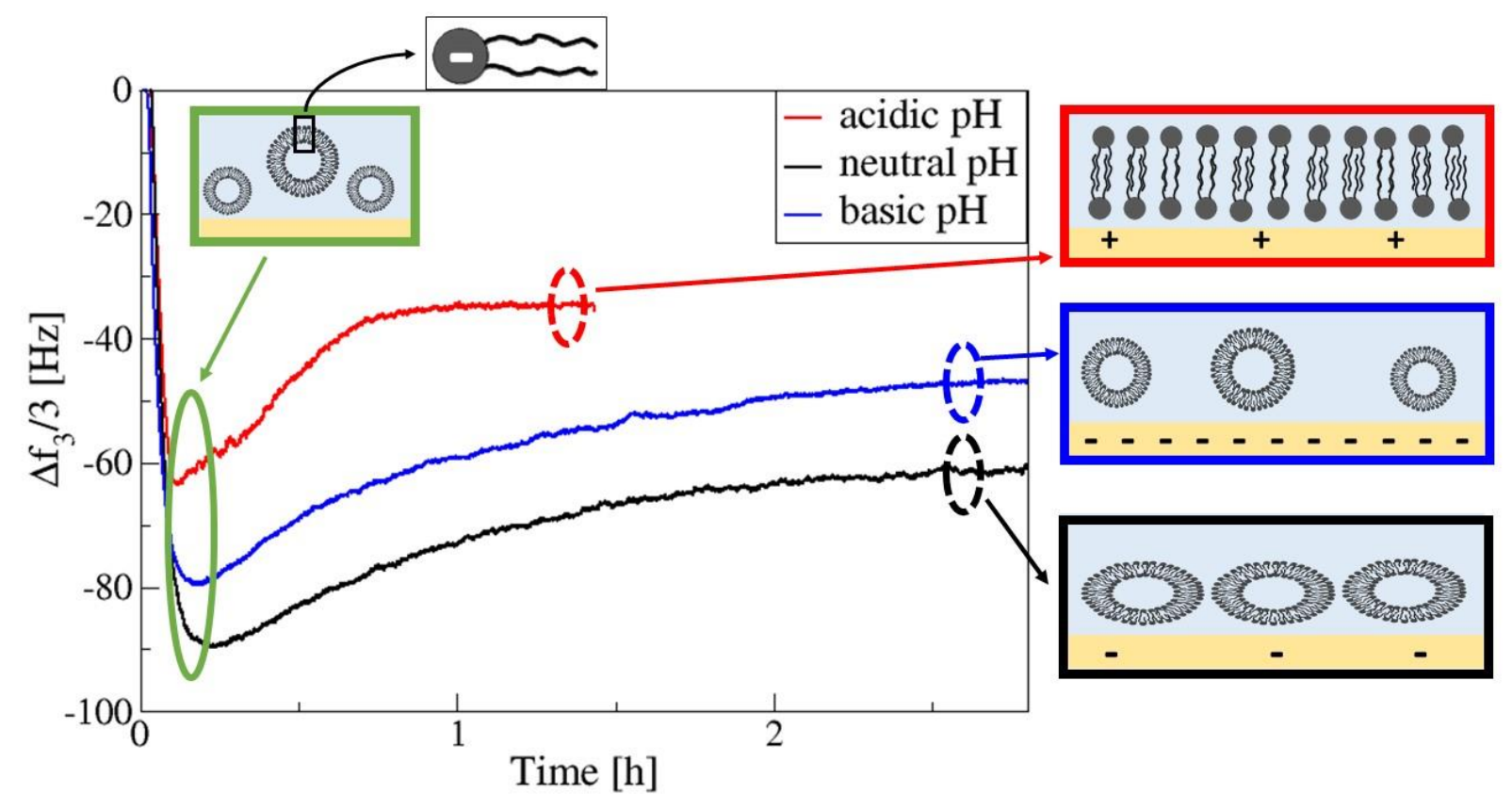

